\title{
On the Virtues of Privatization When Government is Benevolent
}

by

\author{
Christoph Lülfesmann *
}

Revised version - June 6, 2003

\begin{abstract}
This paper shows that privatizing a public firm can be welfare improving even if the government is a welfare maximizer. In our model, the firm's owner which can either be a profit maximizing entrepreneur (under private ownership) or a benevolent government (under public ownership), employs a manager whose effort can invent an innovative production technology. Wage arrangements in each governance mode are optimal given the verifiable information. All parties behave rationally and the information structure does not change when the firm is privatized. Still, privatization is shown to be preferable in a variety of situations. Only if ongoing production under an established technology is inefficient, government ownership is always dominant and facilitates a first-best outcome.
\end{abstract}

Keywords: Privatization, Incomplete Contracts, Innovative Technologies. JEL-Classification: D23, H57, L51.

*Department of Economics, Simon Fraser University, 8888 University Drive, Burnaby, B.C. V5A 1S6, Canada. Email: cluelfes@sfu.ca. Phone: +1-(604)-291 5813. This paper has been presented in seminars at Bloomington/Indiana, Bonn and at the IIPF conference in Moscow. I wish to thank seminar participants and Dieter Bös, Lans Bovenberg, Giacomo Corneo, Eckhard Janeba, Ashok Kaul, Anke Kessler, Urs Schweizer and an Associate Editor of this journal for helpful comments and suggestions. All remaining errors are mine. Financial support by Deutsche Forschungsgemeinschaft, Sonderforschungsbereich 303 at the University of Bonn, is gratefully acknowledged. 


\section{Introduction}

The last decade has witnessed a widespread political agreement on the welfareenhancing effects of private governance. Public officials now assess privatization as a proper instrument to reduce slack, implement more efficient production technologies, or promote a faster development of promising product innovations. This view has also been supported by empirical studies which largely report positive effects of privatization on the firm's productive efficiency. ${ }^{1}$

Perhaps surprisingly, economic theory has more difficulties to identify the merits of privatization, in particular when the government is assumed to behave purely benevolent. The public-choice oriented branch of the literature stresses the private goals of government officials, and welcomes privatization as a means to constrain self-interested bureaucrats or politicians [Shapiro and Willig (1990), Boycko, Shleifer and Vishny (1996)]. In a similar spirit, some authors start from the empirical observation that inefficient contracting prevents efficient outcomes in public firms: for example, governments often refrain from signing incentive contracts with their managers and workers, which can be seen as an exogenous impediment to optimal performance [see, e.g., Vickers and Yarrow (1988) and Bös (1991)].

These approaches provide some reasonable arguments in favor of privatization. The negative picture of government behavior that these models paint, however, is not always justified. This is in particular so when public decisionmakers are subject to effective democratic control. According to the recent literature in political economy, politicians are indeed forced to restrain their tendencies to pursue private objectives when they stand up for reelection [for a comprehensive survey, see Persson and Tabellini (2000)]. In this light, the previous literature fails to answer the more fundamental question whether a rationally acting and benevolent government may be less suited to operate a firm than a private, profit-maximizing entrepreneur. The present paper addresses this important question.

The arguments of Coase (1937) and Williamson (1985) seem to imply that privati-

\footnotetext{
${ }^{1}$ For recent empirical assessments of international privatization programmes, see Megginson, Nash and van Randenborgh (1994), and Martin and Parker (1997) for the UK. Megginson and Netter (2001) provide a comprehensive survey of the empirical literature.
} 
zation can never be optimal when one subscribes to a benevolent and rational view of government. As these authors forcefully argued, it would be optimal to organize the entire economy as a single firm which is governed by a chairman. This chairman (the benevolent government in our context) selectively intervenes into the decisions of lower hierarchy levels whenever an intervention increases the 'profit' of the whole organization, thereby internalizing al the external effects across the divisions of the organization. Only the more recent property rights approach, which starts with the pioneering article by Grossman and Hart (1986), has resolved this so-called 'Williamson puzzle' and has succeeded in identifying the vices of centralized ownership. The main methodological corner stone of this theory is the idea that contracts are necessarily incomplete, which renders it possible to study the implications of different governance modes structures. $^{2}$

The present article follows this methodological paradigm. ${ }^{3}$ We analyze the incentives of a welfare-maximizing government as a representative of the society to privatize a public firm under incomplete contracting. Specifically, we assume that an initial labor contract between the firm's owner (the government or a private entrepreneur) and its management cannot condition on the subsequent invention and implementation of an innovative and more efficient production technology. ${ }^{4}$ After signing an initial wage contract, the firm's manager can undertake a non-contractible effort to develop this innovative process. Irrespective of managerial success, the firm can subsequently operate on the output market, or it shuts down. We assume that the enterprise should remain in business at least if the innovative technology has become available. Nevertheless, the firm owner has a credible threat of shutdown when the precontracted managerial wage exceeds the owner's utility from operating on the output market.

\footnotetext{
${ }^{2}$ When 'comprehensive' contracts are feasible, all agents can be tied by a so called 'grand contract' and property rights are not a meaningful concept. Contracts are comprehensive when they are contingent on any relevant contingency that is jointly observed by the parties. Therefore, even informational asymmetries between principal and agent, which are the focus of the standard contract-theoretical literature, do not preclude the optimality of grand contracts. See, for example, Hart and Holmström (1987), Holmström and Tirole (1989) and Hart (1995).

${ }^{3}$ The application of incomplete contracting models to public policy issues is relatively new; for excellent treatments, see Tirole (1994) and Dixit (1996). Shleifer (1998) surveys arguments from the recent literature on privatization.

${ }^{4}$ For similar approaches in the context of bilateral trade models, see Aghion and Tirole (1994), Hart and Moore (1999), Segal (1999), and Lülfesmann (2001).
} 
In our model, wage renegotiation will arise in equilibrium whenever a credible shutdown threat exists but it is efficient to remain in business. The possibility to renegotiate ensures ex-post efficient production decisions in either regime. ${ }^{5}$ Because the objective functions of the respective owner differ, however, the two governance modes crucially differ in the set of situations where renegotiation under a given wage contract actually occurs. If the firm has remained public, the benevolent government has a relatively soft budget constraint [Kornai (1986)] because its utility is the sum of consumer surplus and profits. Conversely, the profit-maximizing owner of a private firm is subject to a tighter budget constraint because she does not internalize consumer surplus from ongoing production.

These endogenously emerging differences at the bargaining stage give rise to the following results: in a first scenario, we suppose that the firm's established production technology has become so outdated that either type of owner goes out of business unless an innovative technology can be implemented. In this case which resembles a standard moral hazard type of situation, there exists an optimal initial wage contract that leads to efficient investments and a first-best outcome under public governance: the optimal wage arrangement is a contract where the manager reaps the entire social surplus (minus a constant) if the firm remains in business. In contrast, underinvestments prevail if the firm has been privatized, and public governance is strictly welfare preferred over private ownership. This outcome confirms the intuition that a welfaremaximizing principal must attain at least the same welfare level as a private principal whose objective function exhibits profit rather than welfare objectives. ${ }^{6}$

However, in a second and possibly more realistic scenario where ongoing production under the established 'basic' technology remains valuable, our previous results are reversed. While public ownership may trigger suboptimal investments under the optimal wage contract, private ownership of the firm may now facilitate an efficient outcome.

\footnotetext{
${ }^{5}$ For concreteness, we suppose that renegotiations lead to the Nash-bargaining solution where the surplus from ongoing production is evenly shared among respective owner and manager.

${ }^{6}$ Aghion and Tirole (1994) also consider a model in which an agent innovates for a principal, and where the value of the innovation is non-contractible. In contrast to the present paper, their model disregards monetary contracts between principal and agent and focuses instead on the assignment of property rights on forthcoming innovations. According to this restriction, Aghion and Tirole do not achieve a first best result. Another important difference is that the agent is not indispensable for implementing the innovation in their model: once it is invented, the principal can freely use it if she is the owner.
} 
Intuitively, the efficient level of managerial effort is reduced relative to the previous scenario because the firm can continue to operate even if no process innovation becomes available. Hence, the underinvestment problem in private procurement is alleviated and may entirely disappear.

The manager of a public firm, however, now overinvests under the wage contract that was optimal in the scenario without viable basic technology: while he continues to gain the full marginal social surplus when the innovative technology is invented, he appropriates only half of this surplus when the innovation is unavailable and the firm continues to use the basic technology after reneging the managerial wage. The manager's payoff difference between these two events exceeds the corresponding difference in social surplus, which leads him to expend too much effort. We also show that there may exist no other initial wage contract which restores efficient investments in a public firm. As a consequence, public governance may fail to reach the efficiency frontier and privatization may be strictly superior from the government's point of view. Parameterizing the probability with which production under the basic technology remains valuable, we also derive clearcut conclusions on the set of economic situations where one governance structures dominates the other: loosely speaking, the stronger the pressure to innovate, the better is the relative performance under nationalization and vice versa.

Several elements of our argument are worth to be emphasized. Our framework allows to compare governance modes exclusively in terms of their efficiency implications regarding managerial effort. We can do so for two main reasons. ${ }^{7}$ First, because of renegotiation the ex-post efficient production or shutdown decision is taken in either regime. Second, distributional considerations can be handled via lump-sum components in the initial contracts, in particular, the government can privatize in a way that it extracts all quasi-rents which a private entrepreneur may subsequently enjoy.

While our findings are partially in line with the informal literature on soft budget constraints in public firms due to time inconsistency problems, the logic of our results is very different. ${ }^{8}$ According to a well-known argument on the desirability of privatization,

\footnotetext{
${ }^{7}$ In our framework, regulation ensures that a private firm produces the efficient output level. An alternative justifications for this assumption is the feasibility of perfect price discrimination.

${ }^{8}$ Kornai (1986) introduced the notion of soft budget constraints. See also Maskin (1999) and in particular Kornai, Maskin and Roland (2002) for a recent assessment of theoretical developments.
} 
a government's welfare interest renders any shutdown threat noncredible even if the production costs in a public firm are inefficiently high. A public manager thus expects his job to be secure even if he remains lazy, and has no incentive to engage in cost reductions. Conversely, a private owner has a credible threat to shut down the firm and dismiss the manager when costs are high and the firm goes bankrupt. As a response, the manager works harder to avoid losing his job [see, e.g., Segal (1998)].

This soft budget constraint argument is intuitive yet it suffers from several flaws. First, it neglects that even a welfare-maximizing owner may initially sign wage contracts with its management which can be renegotiated and therefore do not necessarily coincide with equilibrium wages. Second, and more fundamentally, the argument requires a government commitment not to intervene in the private firm's operations even if its owner takes an inefficient shutdown decision. This commitment which implicitly underlies the argument, though, is sequentially irrational because the government has an interest to bail out a private firm after bankruptcy [see Kornai et al. (2002)]. ${ }^{9}$ If no non-credible commitment is admitted, it remains unclear why a private manager who expects a government bailout works more than his public counterpart. The main goal of the present paper is to demonstrate that private ownership can be the optimal mode of governance even if non-credible commitments are ruled out, and if initial wage contracts can be renegotiated.

Our approach is related to other articles which analyze privatization in incompletecontract frameworks with benevolent governments. Schmidt (1996a,b) posits an interdependency between ownership mode and informational structure. In particular, he assumes that privatization eliminates the government's knowledge on the firm's production costs. The basic trade-off between governance modes is then as follows. Since the government does not observe the realization of production costs after privatization, ex post regulation generates an inadequately low output but also an informational rent for the manager. This informational rent, in turn, provides the manager with incentives to engage in cost reductions ex ante. ${ }^{10}$ Conversely, in a state-owned firm the

\footnotetext{
${ }^{9}$ In practice, governments often subsidize bankrupt private firms. In particular, bail-outs are often observed in industries with monopolistic structures, or in situations where the government aims to protect domestic industries or employment.

${ }^{10}$ In Shapiro and Willig (1990), privatization also erects an informational barrier between regulator and firm. In their model, his bad knowledge prevents the self-interested regulator from pursuing own idiosyncratic goals, which can explain for the benefits of privatization.
} 
government can easily enforce the efficient output level ex post and leave no rent to the manager, but the public manager undertakes no effort at the ex-ante stage since these investments do not raise his salary.

Hart, Shleifer and Vishny (1997) explore the effects of privatization in a model where the firm's manager (or owner-manager after privatization) can invest into cost-reducing and quality-improving technologies, respectively. Under nationalization, the implementation of either technology requires Nash bargaining between manager and government. This implies that the manager recovers only half of the marginal surplus from both activities, and underinvestment follows. After privatization, the owner-manager can unilaterally implement the cost-reducing technology and becomes the residual claimant for that activity. He then invests efficiently in cost reduction which makes privatization the efficient organizational mode. ${ }^{11}$

The present paper may be seen as complementary to these approaches: in contrast to Schmidt, we do not assume a connection between governance mode and informational structure. In contrast to Hart et al., we allow for more realistic wage contracts as we do not impose the assumption that a public manager cannot be made residual claimant for his own cost savings (while a private manager-owner can). ${ }^{12}$

The remainder of the paper is organized as follows. Section 2 introduces and solves the basic model. Section 3 extends this model by introducing a viable basic technology. Section 4 summarizes and discusses the main results, and Section 5 concludes.

\footnotetext{
${ }^{11}$ This is not the case if, as is assumed in Hart et al., implementing a cost reduction reduces the quality of services delivered. In this case, the private owner-manager overinvests in cost reduction. To implement quality improvements, the private owner still has to bargain with the government, and therefore underinvests in the same way as a public manager.

${ }^{12}$ In addition, the firm's operations are delegated to to an employed manager in our model. Delegation would invalidate the benefits of privatization in Hart, Shleifer and Vishny, while Schmidt (1996b) shows that the outcome remains qualitatively unaffected provided that the employed manager is an empire builder.
} 


\section{A Simple Framework}

\subsection{Model Description}

There are three parties, the government $(G)$, a private owner $(P)$, and a manager $(M)$. All parties are risk neutral and have complete information throughout the game. Initially, the government owns a monopolistic enterprise that can be sold to a private entrepreneur. If the government wants to privatize, $G$ and $P$ agree on a sales contract and the private entrepreneur becomes residual claimant for the firm's nonverifiable return streams. ${ }^{13}$ If the enterprise is not privatized, it remains in public hands. In either regime, a self-interested (and indispensable) manager $M$ runs the firm. After the governance structure has been chosen, owner $O \in\{G, P\}$ and manager $M$ sign a wage contract $w$ that is detailed below.

Before output is produced, $M$ can invest in the development of a process innovation which (when implemented) lowers the fixed costs of production from $\tilde{\delta}>0$ to zero. The corresponding non-contractible effort is indicated as $e$, and represents the exante probability with which the innovation is invented. Throughout the paper, we assume that the manager's innovative success in unverifiable in the sense that third parties (such as courts) are unable to observe it. ${ }^{14}$ We suppose that the manager's investment costs are an increasing and convex function $\psi(e)$ and in order to ensure interior solutions, impose the Inada conditions $\psi_{e}(0)=0$ and $\psi_{e}(e) \rightarrow \infty$ for $e \rightarrow 1$ (subscripts denote derivatives).

After it has become clear whether the innovative technology $T_{I}$ is available, the firm can take up production $y$. Defining $S(y)$ as net consumer surplus and $\Pi(y)=R(y)-C(y)$ as the firm's variable profits (i.e., revenues minus variable production costs), the welfare-

\footnotetext{
${ }^{13}$ Below, we will see that the optimal privatization contract stipulates not only a fixed sales price $t$, but also entails two regulatory components: first, it allows the government to prescribe a production level after the state of the world has been realized (or, equivalently, a consumer price). Second, the contract specifies a wage level $w$ which is paid to the manager. Alternatively, if ownership changes do not render previous wage contracts spurious, $G$ and $M$ can agree on a salary before the privatization contract is signed.

${ }^{14}$ Otherwise, the model would be trivial. Since manager and owner are risk-neutral and no wealth constraints are imposed, a contract that directly conditions on the innovative success would easily implement the first best. See below.
} 
maximizing quantity is assumed to be positive and represented by

$$
y^{F B}=\arg \max _{y}\{S(y)+\Pi(y)\} .
$$

When the welfare-government has retained ownership, it will always set marginal-cost prices and produce the efficient quantity. In contrast, a private owner has an intrinsic interest to choose monopoly prices in order to maximize profits. Therefore, it is optimal for the government to preserve the right to regulate the privatized firm's output level by imposing marginal-cost pricing, and $y^{F B}$ again prevails. ${ }^{15}$ Thus, governance structures do not differ in their allocative implications. Throughout the paper, we will assume that

$$
\Pi\left(y^{F B}\right)>0
$$

so that the private owner's gross-of-wages profits are positive even if she produces the efficient (rather than the profit-maximizing) quantity. Since $y^{F B}$ equalizes consumer price and marginal costs, (2) always holds under the standard assumption that the variable cost function is convex in output.

If the manager's effort is unsuccessful and he did not invent the new production technology, the firm can still operate under an established 'basic' technology $T_{B}$ with positive fixed costs, $\tilde{\delta}>0$. Throughout the present section, we suppose that $\tilde{\delta}>S\left(y^{F B}\right)+\Pi\left(y^{F B}\right)$. This assumption reflects a scenario where changes in market conditions or increases in fixed costs have made the basic technology so ineffective that the firm should be shut down when no technology change takes place. ${ }^{16}$

Adopting the incomplete-contracting paradigm, we suppose that the invention and the returns from the innovative technology are non-contractible. While the firm owner observes whether managerial effort is successful and a useful invention is made, third parties such as the courts often do not have the same information. Also, creative accounting may allow an owner to hide the relevant operating profits among his many activities [see, e.g., Aghion and Tirole (1994)].

\footnotetext{
${ }^{15}$ While it may be unrealistic to suppose that regulation can ensure first-best production levels, we deliberately impose this assumption in order to simplify the exposition and to concentrate on the incentive effects of governance modes. Ceteris paribus, imperfect regulation clearly reduces the value of privatization. Notice that first-best production does not require regulation if the private firm is able to perfectly price discriminate among consumers. The same result prevails when consumer demand is completely unelastic [see e.g. Hart et al. (1997)].

${ }^{16}$ In the subsequent Section 3, we will allow for a 'viable' basic technology where $\tilde{\delta}$ can be so small that the firm should continue to operate even if $T_{I}$ has not been invented.
} 
In addition, owner $O$ and manager $M$ cannot be forced to produce if the corresponding utility of (at least) one party is smaller than its respective default payoff. ${ }^{17}$ Combining the above assumptions, the managerial wage can condition only on the firm's subsequent operation, and we can indicate his employment contract as $\left(w_{0}, w_{1}\right)$ : while $M$ obtains $w_{1}$ if the firm remains in business and production is taken up, he receives a precontracted redundancy payment $w_{0}$ if the firm shuts down. Define $\Delta w \equiv w_{1}-w_{0}$. Then, the manager is willing to produce if and only if

$$
U^{M}(w, 1)=w_{1} \geq w_{0}=U^{M}(w, 0) \quad \Longleftrightarrow \quad \Delta w \geq 0 .
$$

where $U^{M}(w, 1)$ and $U^{M}(w, 0)$ represent his post-investment utility levels when the firm remains in business or closes down, respectively.

The government is benevolent; its objective function exhibits the sum of net consumer surplus and producer surplus minus wages that are paid to the manager. ${ }^{18}$ Accordingly, if the firm has remained under public ownership, the government agrees to production under the initial wage contract if

$$
U^{G}(w, 1)=S\left(y^{F B}\right)+\Pi\left(y^{F B}\right)-w_{1} \geq-w_{0} \quad \Longleftrightarrow \quad \Delta w \leq S\left(y^{F B}\right)+\Pi\left(y^{F B}\right) .
$$

Conversely, the private entrepreneur's utility is defined as profits minus wage payments. Hence, she cannot credibly insist on renegotiation and agrees on production if

$$
U^{P}(w, 1)=\Pi\left(y^{F B}\right)-w_{1} \geq-w_{0} \quad \Longleftrightarrow \quad \Delta w \leq \Pi\left(y^{F B}\right) .
$$

Accordingly, production takes place under the initial terms of contract if and only if

$$
\begin{aligned}
S\left(y^{F B}\right)+\Pi\left(y^{F B}\right) \geq \Delta w \geq 0 \quad \text { if } O=G \\
\Pi\left(y^{F B}\right) \geq \Delta w \geq 0 \quad \text { if } O=P .
\end{aligned}
$$

\footnotetext{
${ }^{17}$ Hence, the labor contract is a contract 'at will' that does not incorporate individual breach penalties. Labor relationships are regularly governed by at will contracts [see MacLeod and Malcomson (1993) and Malcomson (1997)]. Notice that if either effort, returns, or the invention itself can be verified, there exist simple incentive contracts which resolve the manager's moral hazard problem under both governance modes.

${ }^{18}$ For simplicity, we do not incorporate shadow costs of public funds, $\lambda$, nor do we suppose that the government values the manager's utility as parameterized by some multiplier $\lambda^{M}$. Positive values $\lambda, \lambda^{M}$ would modify the government's objective function to $U^{G}=S(\cdot)+\left[\Pi(\cdot)-w_{1}\right](1+\lambda)+\lambda^{M} U^{M}$ [see Laffont and Tirole (1993)], but not affect our qualitative results.
} 
Note that, even for initial contracts that violate (6) and/or (7), $O$ and $M$ will still agree to start production whenever the innovation has been invented. However, this ex-post efficient decision then requires renegotiation between $O$ and $M$ because exactly agent credibly refuses the ongoing operation of the firm under the initial terms of contract. In line with the literature, we suppose that the outcome of renegotiation is described by the Nash-bargaining solution: under this rule, owner and manager receive their default payoffs $-w_{0}$ and $w_{0}$, respectively, while the joint surplus from production the bargaining surplus - is evenly shared. If the innovation has not been invented, there is no room for renegotiation because production is inefficient and there exists no contract (either initially signed or renegotiated) under which both parties would agree on further production. Therefore, the firm is shut down and the manager receives the precontracted redundancy payment $w_{0}$. (Later on, we will allow for a viable basic technoloogy where the firm remains in operation even if $T_{I}$ is not available; see Section 3 below).

Taken together, we consider the following stage game under complete information:

- Stage 0: The government decides whether to privatize the public enterprise. In case of privatization, the firm is sold to a profit-maximizing entrepreneur at a fixed sales price $t$ that extracts all future profits. Moreover, the government retains the right to decide on the subsequent output level $y$, and obliges the private owner to make a certain wage offer at stage 1 .

- Stage 1: Owner and manager sign a labor contract $\left(w_{0}, w_{1}\right)$ that can be contingent on the firm's subsequent operation.

- Stage 2: The manager undertakes a nonmonetary investment (an effort). A higher effort level increases the probability that an innovative production technology $T_{I}$ becomes available to the firm.

- Stage 3: Nature decides whether $T_{I}$ is invented.

- Stage 4: The innovative technology $T_{I}$ (if available) can now be implemented, possibly after $O$ and $M$ renegotiated the precontracted wage. Alternatively, the enterprise is shut down, in which case $M$ receives a redundancy payment and the game ends. 
- Stage 5: Output $y^{F B}$ is produced and sold to consumers, wage payments are provided. The game ends.

As a benchmark for subsequent reference, we compute the effort level that maximizes welfare (and the government's ex-ante objective function $u^{G}(\cdot)$ )

$$
W(e)=u^{G}(e)=e\left[S\left(y^{F B}\right)+\Pi\left(y^{F B}\right)\right]+(1-e) 0-\psi(e) .
$$

Accordingly, the first-best investment level $e^{F B}$ is implicitly defined by

$$
\psi_{e}\left(e^{F B}\right)=S\left(y^{F B}\right)+\Pi\left(y^{F B}\right) .
$$

A first-best outcome then requires that $M$ exerts $e^{F B}$, and that the welfare-optimal quantity $y^{F B}$ is produced whenever the innovative technology has been invented and implemented. In the next Section, we will examine whether there exist ex-ante contracts $\left(w_{1}, w_{0}\right)$ which render a first-best outcome feasible under either governance structure.

\subsection{Equilibrium Analysis}

We are now prepared to solve the model. Since we know that the production level (if any) will be $y^{F B}$ under both governance structures, we are mainly concerned with managerial investments in presence of renegotiation. Hence, we start our analysis at date 2 where the privatization decision has been taken and a wage contract between $O$ and $M$ has been signed. Define the manager's expected utility from an ex-ante point of view as

$$
u^{M}(w)=e U^{M}(w, 1)+(1-e) U^{M}(w, 0)-\psi(e)=w_{0}+e\left[U^{M}(w, 1)-w_{0}\right]-\psi(e)
$$

and recall that $U^{M}(\cdot, 1)$ and $U^{M}(w, 0)$ indicate his continuation utility in states where the innovation has been invented or has not been invented, respectively. Note that the redundancy payment $w_{0}$ allows to divide total surplus between $O$ and $M$ in any desired way, while investment incentives depend only on $\Delta w$. Moreover, manager and owner will agree upon an initial contract where $M$ 's expected equilibrium utility is at least as large as his exogenous reservation payoff $\bar{u}^{R}$, i.e., $u^{M}(w) \geq \bar{u}^{R}$. In what follows, we characterize equilibrium wages for the whole range of initial compensation 
schemes, and then compute the manager's investment level under either governance structure. A rational government should privatize at date 0 if and only if, under the optimal wage contract, private governance allows for a welfare improvement over the public ownership regime.

\section{Public Governance}

Suppose that the government did not privatize at date 0 . Thereafter, it will then sign a labor contract with the public manager. Since $G$ has the capacity to always command the welfare-optimal production level $y^{F B}$ ex post, we only have to examine whether some initial contract $\left(w_{0}, w_{1}\right)$ leads $M$ to choose efficient investments. Recalling that the initial salary $w_{1}$ will be renegotiated if $\Delta w<0$ or $\Delta w>S\left(y^{F B}\right)+\Pi\left(y^{F B}\right)$, we can calculate equilibrium wages $w_{1}^{e}$ (which coincide with the manager's continuation utility) as a function of the initial wage contract,

$w_{1}^{e}(w)=U^{M}(w, 1)=\left\{\begin{array}{c}w_{1} \quad \text { if } S\left(y^{F B}\right)+\Pi\left(y^{F B}\right) \geq \Delta w \geq 0, \\ w_{0}+\left(S\left(y^{F B}\right)+\Pi\left(y^{F B}\right)\right) / 2 \quad \text { otherwise. }\end{array}\right.$

Whenever both parties prefer production under the initial terms of contract to a shutdown, no renegotiation occurs. Conversely, when the initial wage (difference) is negative or larger than gross-of-wages welfare, renegotiations become necessary to ensure an ongoing operation of the firm. Recall that the redundancy payment $w_{0}$ will never be renegotiated: when the development of the innovation was unsuccessful, it is ex post efficient to shut down the firm; the owner refrains from production and $w_{0}$ is not revised because the parties face a zero-sum game. Inserting these equilibrium figures into (10) and maximizing, the utility-maximizing investment level $e^{G}$ is implicitly defined by

$$
\psi_{e}\left(e^{G}(w)\right)=\left\{\begin{aligned}
\Delta w & \text { if } S\left(y^{F B}\right)+\Pi\left(y^{F B}\right) \geq \Delta w \geq 0, \\
\left(\left(S\left(y^{F B}\right)+\Pi\left(y^{F B}\right)\right)\right] / 2 & \text { otherwise. }
\end{aligned}\right.
$$

It is now straightforward to interpret these equilibrium efforts: under any contract that will be renegotiated on the equilibrium path, $M$ underinvests because he obtains only a fraction $1 / 2$ rather than the full social return on his investments. Conversely, in the contract range where renegotiation can be avoided, $e^{G}($.$) strictly increases in$ $\Delta w$, and an initial contract characterized by $\Delta w^{*}=S\left(y^{F B}\right)+\Pi\left(y^{F B}\right)$ implements efficient investments. Under any labor contract with this characteristic, $M$ receives the full social return from his effort minus a constant and therefore invests efficiently. 
Accordingly, public governance leads to a first-best outcome when the government proposes an optimal initial labor contract.

\section{Private Governance}

After the firm has been privatized and a wage contract has been signed, the manager's continuation utility is again defined by (10). His actual equilibrium payoff, though, differs from the one he undertakes under public governance since equilibrium wages for given initial contracts may not coincide. To see this, recall (7) to find that

$$
U^{M}(w, 1)=w_{1}^{e}(w)=\left\{\begin{aligned}
w_{1} & \text { if } \Pi\left(y^{F B}\right) \geq \Delta w \geq 0, \\
w_{0}+\Pi\left(y^{F B}\right) / 2 & \text { otherwise. }
\end{aligned}\right.
$$

The utility representation in (13) reflects that the private owner has a harder budget constraint than the government. $P$ can credibly threaten to shut down the firm when the wage is above gross profits, even if it is smaller than gross welfare. In contrast to the traditional implications of hard and soft budget constraints, however, the present analysis recognizes that renegotiation ensures efficient production in equilibrium. Noting that $\Delta w \leq \Pi\left(y^{F B}\right)$ is now necessary to prevent renegotiation, we find that the maximum effort level is attained by a contract characterized by $\Delta w=\Pi\left(y^{F B}\right)$ under which $\psi_{e}\left(e^{P}\right)=\Pi\left(y^{F B}\right)$ so that $e^{P}<e^{F B}$. The reason for this underinvestment is very intuitive: since the private owner's valuation of production is smaller than the social valuation, he cannot credibly promise the manager a wage difference which is high enough to make $M$ residual claimant with respect to welfare. ${ }^{19}$

We can now state the following proposition:

Proposition 1. Suppose that it is efficient to shut down the firm unless the innovative technology is invented. Then, a first-best result is attained under public governance, while suboptimal investments prevail after privatization.

According to this result, private ownership is not the efficient form of governance when a technology change is a precondition for the firm's survival. Perhaps in tension with common beliefs, privatization is not a means to enhance managerial effort in

\footnotetext{
${ }^{19}$ It is easy to see that government and owner will indeed agree on a wage $w$ satisfying $\Delta w=\Pi\left(y^{F B}\right)$ in the initial privatization contract. Notice that in the setting of the present Section, $P$ will voluntarily offer the same wage arrangement even if the privatization contract does not stipulate $w$. This is because the implied effort level maximizes the joint payoff $e \Pi\left(y^{F B}\right)-\psi(e)$ of $P$ and $M$.
} 
situations where optimal labor contracts are allowed for. Our result also suggests that the government's soft budget constraint - here interpreted as its intrinsic willingness to pay high wages - has a positive effect on the attainable outcome. ${ }^{20}$ The next section will show that these implications may be reversed when a failure to innovate does not necessarily imply a shutdown of the firm.

\section{$3 \quad$ Viable Basic Technology}

\subsection{The Model}

In the basic model of Section 2, we supposed that the firm's future survival depends on the successful development of an innovative production technology. This case was meant to reflect an economic situation where market conditions have changed so drastically, or established production processes have become so ineffective, that it is welfareefficient to shut down the firm when no cost reductions (in our model, a decrease in fixed costs $\tilde{\delta}$ ) are realized. The present section abandons this extreme assumption, and analyzes a more general scenario where it can be efficient (and even profitable for a private owner) not to go out of business even if no innovative technology is implemented.

To accommodate this scenario, we extend the previous model in the most simple way. Specifically, we now suppose that, with an exogenous ex ante probability $q$, the fixed $\operatorname{costs} \tilde{\delta}$ which have to be incurred under the basic technology are low enough that ongoing production is efficient and even profitable. We define the fixed costs as a binary random variable $\tilde{\delta} \in\left\{\delta, \delta^{\prime}\right\}, \delta<\delta^{\prime}$ that is drawn by nature at date 3 after $M$ expended his investments. Supposing that $\delta^{\prime}>S\left(y^{F B}\right)+\Pi\left(y^{F B}\right)$, future production becomes inefficient when high fixed $\operatorname{costs} \delta^{\prime}$ are realized. Then, as in the basic model of Section 2, a shutdown cannot be avoided. However, when the low realization of fixed costs $\delta<\Pi\left(y^{F B}\right)\left[<S\left(y^{F B}\right)+\Pi\left(y^{F B}\right]\right.$ prevails, future production remains viable even under the basic technology, and in equilibrium production goes on under either

\footnotetext{
${ }^{20}$ Note that, when $\Pi\left(y^{F B}\right)<0$ so that a private owner is not willing to operate the firm even if $\Delta w=0$, the government will intervene and the governance structure is irrelevant. Conversely, if the government behaves sequentially irrational and does not intervene, a private firm will never start production.
} 
governance structure. Let

$$
q=\operatorname{prob}\{\tilde{\delta}=\delta\}, \quad q \in[0,1]
$$

be the ex-ante probability for low fixed costs, that is, the probability with which the firm remains in operation even if the new technology is not invented. Note that the analysis in the basic model of Section 2 corresponded to an economic environment where $q=0$.

Because innovative and basic technology differ only in the fixed costs of production, the efficient investment level $y^{F B}$ is still determined by (1). On the other hand, our extension affects the first-best optimal investment level $e^{F B}$, which now maximizes

$$
W(e ; q)=u^{G}(e ; q)=e\left[S\left(y^{F B}\right)+\Pi\left(y^{F B}\right)\right]+(1-e) q\left[S\left(y^{F B}\right)+\Pi\left(y^{F B}\right)-\delta\right]-\psi(e)
$$

Differentiating this concave program with respect to $e$, we obtain

$$
\psi_{e}\left(e^{F B}(q)\right)=\left[S\left(y^{F B}\right)+\Pi\left(y^{F B}\right)\right](1-q)+q \delta>0
$$

This solution reflects the uncertainty faced by the manager: with probability $q$, the continuation equilibrium is characterized by ongoing production even if managerial effort was not successful, and the marginal return on investments is just $\delta$. With opposite probability $(1-q)$, the firm's survival requires the invention of $T_{I}$. Therefore, the marginal return from investments in this state is higher because only a successful innovation prevents the firm's shutdown. In the game between owner and manager, renegotiation again leads to the ex-post efficient production decision. For any initial contract the manager chooses his effort level to maximize his utility function

$$
u^{M}(w)=w_{0}+e\left[U^{M}(w, I)-w_{0}\right]+(1-e) q\left[U^{M}(w, B)-w_{0}\right]-\psi(e)
$$

where $U^{M}(w, I)$ and $U^{M}(w, B)$ now indicate his continuation payoff when the innovation has been invented, or it has not been invented but the basic technology remains viable, respectively. Differentiation of this objective function with respect to $e$ yields the manager's equilibrium effort $e^{O}(w, q), O \in\{G, P\}$, which is now implicitly determined as

$$
\psi_{e}\left(e^{O}\right)=U^{M}(w, I)-q U^{M}(w, B)-w_{0}(1-q), \quad O \in\{G, P\} .
$$


The next subsection analyzes both regimes, public and private governance. To simplify the subsequent exposition, define $G_{i}=S\left(y^{F B}\right)+\Pi\left(y^{F B}\right)-\delta_{i}, i \in\{I, B\}$ as the government's ex-post payoff before wage payments when technology $T_{i}$ is implemented [recall that $\left.\delta_{I}=0\right]$. Likewise, we will refer to $P_{i}=\Pi\left(y^{F B}\right)-\delta_{i}$ as a private owner's gross-of-wages profits.

\subsection{Equilibrium Analysis}

\subsubsection{Public governance}

Before we offer a detailed analysis, is is useful to reconsider the contract $\Delta w^{*}=G_{I}$ which was optimal in the setting of Section 2: if $q=0$, this contract leads the manager to invest $e^{G}=S(\cdot)+\Pi(\cdot)$, a level that coincides with $e^{F B}(q=0)$. We will show that the same contract $\Delta w^{*}$ triggers overinvestments for any $q>0$. To see this, note that the manager still obtains the entire social surplus (up to the constant $w_{0}$ ) when the innovation is successfully invented and implemented. However, if the new technology has not become available while the basic technology remains viable (nature has drawn $\tilde{\delta}=\delta$ ), ongoing production is efficient but the government credibly refuses to pay the precontracted salary [note that $\Delta w^{*}=G_{I}>G_{B}$ ]. The parties will then renegotiate the manager's salary scheme downwards, and $M$ recovers only half of social surplus from production when $T_{I}$ has not been invented. As a consequence, his private investment incentives now exceed the socially efficient level and the manager overinvests in order to increase the probability of innovation and to ensure himself the corresponding high salary.

It remains to analyze whether some wage contract other than $\Delta w^{*}$ generates efficient investments. To answer this question, we must again compute the manager's equilibrium effort for all possible initial contracts. Table 1 below summarizes the public manager's equilibrium payoffs as a function of the initially contracted wage differential and the state of nature. ${ }^{21}$

\footnotetext{
${ }^{21}$ Results in Table 1 are computed under the hypothesis that, when both technologies are viable, the manager prefers to work under the efficient technology $T_{I}$ at any given wage. Therefore, no renegotiations arise when both technologies are viable and the initial wage contract is within the interval $G_{B} \geq \Delta w \geq 0$, since the manager cannot credibly threaten to use $T_{B}$ unless the government increases his salary. Alternatively, one could imagine that the implementation of $T_{I}$ imposes some
} 


\begin{tabular}{|c||c|c|}
\hline$\Delta w$ & $\begin{array}{c}T_{I} \text { not invented but } T_{B} \text { viable } \\
U^{M}(w, B)\end{array}$ & $\begin{array}{c}T_{I} \text { invented } \\
U^{M}(w, I)\end{array}$ \\
\hline \hline $0 \leq \Delta w \leq G_{B}$ & $w_{1}$ & $w_{1}$ \\
\hline$G_{B}<\Delta w \leq G_{I}$ & $w_{0}+\left[S\left(y^{F B}\right)+\Pi\left(y^{F B}\right)-\delta\right] / 2$ & $w_{1}$ \\
\hline$\Delta w>G_{I}$ & $w_{0}+\left[S\left(y^{F B}\right)+\Pi\left(y^{F B}\right)-\delta\right] / 2$ & $w_{0}+\left[S\left(y^{F B}\right)+\Pi\left(y^{F B}\right)\right] / 2$ \\
\hline
\end{tabular}

Table 1

These outcomes are easily explained. A precontracted non-negative wage difference is renegotiated only if further production is efficient, but the government is not willing to remain in business under the initial compensation scheme. First, if the innovation has been invented, this implies that any contract characterized by $\Delta w \leq G_{I}$ is never renegotiated, and the manager's equilibrium wage is $w_{1}$. Second, when $T_{I}$ has not become available but the basic technology remains viable, the initial contract is not renegotiated if $\Delta w \leq G_{B}=S(\cdot)+\Pi(\cdot)-\delta\left[<G_{I}\right]$. In all other cases, the parties rescind the precontracted compensation scheme and share gross welfare from production starting from their default payoffs $w_{0}$ and $-w_{0}$, respectively. This gross welfare depends on the production technology that is efficient and utilized in equilibrium.

Inserting the continuation utilities derived in Table 1 into (18), we obtain

$$
\psi_{e}\left(e^{G}(w, q)\right)=\left\{\begin{aligned}
\Delta w(1-q) & \text { if } G_{B} \geq \Delta w \geq 0, \\
\Delta w-q\left(S\left(y^{F B}\right)+\Pi\left(y^{F B}\right)-\delta\right) / 2 & \text { if } G_{I} \geq \Delta w>G_{B}, \\
\left.\left(S\left(y^{F B}\right)+\Pi\left(y^{F B}\right)\right)(1-q)+q \delta\right) / 2 & \text { otherwise. }
\end{aligned}\right.
$$

A comparison with the first-best effort level derived in (16) immediately reveals that, for any $q$, underinvestments prevail for contracts characterized by $\Delta w \leq G_{B}$ or $\Delta w>G_{I}$. Therefore, we can confine attention to the interval $\Delta w \in\left(G_{B}, G_{I}\right]$. Note that

$$
\frac{d e^{F B}(q)}{d q}=-G_{B}<-\frac{G_{B}}{2}=\frac{d e^{G}\left(\Delta w \in\left(G_{B}, G_{I}\right], q\right)}{d q} .
$$

positive switching costs on $M$, who then ceteris paribus prefers the basic technology. Then, any initial wage contract from the interval $\Delta w \leq G_{B}$ will be renegotiated in order to obtain the manager's consent to the efficient technology. While we do not analyze this case to simplify the exposition, one can show that all of our subsequent results still apply. 
Since we know that the upper-boundary wage differential $\Delta w=G_{I}$ implements efficient investments when $q=0$, (20) implies that the same contract induces $M$ to overinvest for any $q>0$. Accordingly, we have the following condition for the implementability of efficient investments under public governance: $M$ must weakly underinvest at the lower bound of the relevant interval, $\Delta w=G_{B}$. Inserting this wage differential into (18) and solving for $q$, we can compute the threshold probability $q^{G}$ as

$$
q^{G}=\min \left\{\frac{2 \delta}{S\left(y^{F B}\right)+\Pi\left(y^{F B}\right)-\delta}, 1\right\} .
$$

This parameter constitutes an upper bound on the range of initial probabilities $q$ where efficient investments are attainable. This finding immediately allows us to state

Proposition 2. Public ownership implements the efficient outcome whenever $q \in$ $\left[0, q^{G}\right]$, whereas the first best is infeasible for any $q \in\left(q^{G}, 1\right]$. Specifically, this inefficiency range is non-empty (i.e., $q^{G}<1$ ) whenever $S\left(y^{F B}\right)+\Pi\left(y^{F B}\right)>3 \delta$.

The proposition asserts that public governance fails to achieve efficiency when the established basic technology remains viable with high probability, and if gross-of-wages welfare is sufficiently large. Inspection also reveals that the threshold probability $q^{G}$ even converges to zero when consumer surplus and/or profits sufficiently exceed the fixed costs $\delta$. Our findings suggest that, for a wide range of economic circumstances, a public enterprise fails to attain the first best even if the government as owner of the firm is purely benevolent. The next subsection explores whether privatization can be a remedy to overcome the investment inefficiencies which prevail under public governance.

\subsubsection{Privatization}

Unlike the government, a profit-maximizing owner is not concerned with consumer surplus. Therefore, she will at stage 4 not agree to any wage payment that exceeds gross profits $P_{i} \equiv \Pi\left(y^{F B}\right)-\delta_{i}, i \in\{I, B\}$. Since $P_{i}<G_{i}$, the interval boundaries $P_{B}$

and $P_{I}$ are now smaller than their counterparts under public governance. As in the public ownership case, we must distinguish between three intervals of initial contracts. Table 2 below summarizes the manager's equilibrium utilities in all states of the world and for all initial compensation schemes. 


\begin{tabular}{|c|c|c|}
\hline$\Delta w$ & $\begin{array}{c}T_{I} \text { not invented but } T_{B} \text { viable } \\
U^{M}(w, B)\end{array}$ & $\begin{array}{c}T_{I} \text { invented } \\
U^{M}(w, I)\end{array}$ \\
\hline \hline $0 \leq \Delta w \leq P_{B}$ & $w_{1}$ & $w_{1}$ \\
\hline$P_{B}<\Delta w \leq P_{I}$ & $w_{0}+\left[\Pi\left(y^{F B}\right)-\delta\right] / 2$ & $w_{1}$ \\
\hline$\Delta w>P_{I}$ & $w_{0}+\left[\Pi\left(y^{F B}\right)-\delta\right] / 2$ & $w_{0}+\left[\Pi\left(y^{F B}\right)\right] / 2$ \\
\hline
\end{tabular}

Table 2

Inserting these utilities into (18), we obtain the equilibrium effort defined by

$$
\psi_{e}\left(e^{P}(w, q)\right)=\left\{\begin{aligned}
\Delta w(1-q) & \text { if } P_{B} \geq \Delta w \geq 0 \\
\Delta w-q\left(\Pi\left(y^{F B}\right)-\delta\right) / 2 & \text { if } P_{I} \geq \Delta w>P_{B} \\
\left(\Pi\left(y^{F B}\right)(1-q)+q \delta\right) / 2 & \text { otherwise. }
\end{aligned}\right.
$$

Again, it is easy to check that only the wage interval $\Delta w \in\left(P_{B}, P_{I}\right]$ is a candidate for efficient investments. Note that

$$
\frac{d e^{P}\left(q, \Delta w \in\left(P_{B}, P_{I}\right]\right)}{d q}=-\left[\Pi\left(y^{F B}\right)-\delta\right]>-\left[S\left(y^{F B}\right)+\Pi\left(y^{F B}\right)-\delta\right]=\frac{d e^{F B}(q)}{d q}
$$

and recall from our previous analysis that the manager underinvests for $q=0$. Accordingly, we have a necessary (though not sufficient) prerequisite for efficient investments in a nonempty interval of parameters $q$ : namely, the manager overinvestments for $q=1$ under an initial contract characterized by $\Delta w=P_{I}$. Inspection shows that this condition

$$
e^{P}\left(\Delta w=P_{I}, q=1\right)=\frac{\Pi\left(y^{F B}\right)+\delta}{2}>\delta=e^{F B}(q=1)
$$

indeed applies because $\Pi\left(y^{F B}\right)>\delta$. Inserting $\Delta w=P_{I}$ into (18)) and solving for $q$, we can also define $\underline{q}^{P}<1$ as the minimum ex-ante probability $q$ for which (weak) overinvestments can be generated under private governance. Conversely, underinvestments are unavoidable for any $q<q^{P}$.

We obtain

$$
\underline{q}^{P} \equiv \frac{S\left(y^{F B}\right)}{S\left(y^{F B}\right)+\left[\Pi\left(y^{F B}\right)-\delta\right] / 2} .
$$

Note that $\underline{q}^{P} \in(0,1)$. Finally, we must check whether the manager still overinvests at the interval's lower boundary, $\Delta w=P_{B}$, which also is an impediment to efficiency. 
Inserting this wage differential into (18) and solving for the threshold value $\bar{q}^{P}$, we obtain (note that $\bar{q}^{P}>\underline{q}^{P}$ )

$$
\bar{q}^{P} \equiv \min \left\{\frac{S\left(y^{F B}\right)+\delta}{S\left(y^{F B}\right)+\left[\Pi\left(y^{F B}\right)-\delta\right] / 2} ; 1\right\} .
$$

These computations allow us to state the following proposition.

Proposition 3. Private ownership implements efficient investments and a first-best outcome for any $q$ from the nonempty interval $\left[q^{P}, \bar{q}^{P}\right]$ where $q^{P} \in(0,1)$ and $\bar{q}^{P} \in$ $\left(\underline{q}^{P}, 1\right]$. Specifically, efficiency is attained for any $q \geq \underline{q}^{P}$ whenever $\Pi\left(y^{F B}\right)<3 \delta$.

Proposition 3 shows that private ownership may trigger efficient investments in our extended scenario with a viable basic technology. It also demonstrates that the efficiency ranges of public and private governance are complementary. Under privatization, efficiency is always unattainable if $q$ is small. This result is very intuitive: as has been shown in Section 2, the parties face a (variant of a) standard moral hazard problem when the basic technology is never viable, and efficient investments can be implemented by a principal whose objective function reflects welfare goals. Conversely, a private owner cannot credibly commit to pay a salary in excess of her gross-of-wages profit from the innovative technology. At the highest credible wage level that is not renegotiated, $\Delta w=P_{I}$, the manager's investment incentives are still suboptimal.

Under economic conditions where it is welfare-efficient to keep the firm in business even if no innovative production technology is invented and implemented, this outcome changes drastically for the following reason. An increase in $q$ decreases the first-best investment level because consumer surplus and variable profits are realized even if no innovation takes place. Likewise, the equilibrium effort under any ownership structure decreases for wages in the relevant intervals $\Delta w \in\left(G_{B}, G_{I}\right]$ (public ownership) and $\Delta w \in\left(P_{B}, P_{I}\right]$ (private ownership), respectively. This reduction in equilibrium investments, however, is strictly smaller than the corresponding reduction in the first-best effort because the manager accrues only half of total surplus when ongoing production under the basic technology is efficient. While the government may then be unable to prevent an overshooting of investments, the same investment-enhancing effect (relative to the first best) pushes a private manager's equilibrium effort towards the first best 
benchmark. As a consequence, the welfare ranking of both governance structure may may be reversed.

If $\Pi\left(y^{F B}\right)<3 \delta \Leftrightarrow \bar{q}^{P}<1$, overinvestments do never arise under privatization if the parties agree on the lowest wage from the interval $\Delta w \in\left(P_{B}, P_{I}\right]$. Then, private ownership implements a first-best outcome for any $q \geq \underline{q}^{P}$, i.e., for any (large) $q$ where an initial contract can prevent underinvestments. If consumer surplus becomes more important, the threshold probabilities $\underline{q}^{P}$ and $\bar{q}^{P}$ increase: in the limit where $S\left(y^{F B}\right)$ converges to infinity, private governance triggers efficiency if and only if $q=1$. This limit case nicely illustrates the complementary nature of public and private governance, because under public governance a first best requires that $q=0$ if $S(\cdot) \rightarrow \infty$.

Our results suggest that the intrinsically harder budget constraint of a private owner may facilitate a first best in situations where public governance fails to achieve efficiency. Importantly, though, the mechanism at work in our model differs substantially from that identified in the informal literature on soft budget constraints: in contrast to this literature, we considered a setting where the privatized firm remains in operation whenever this is optimal from a welfare point of view. As an implication, governance modes do not differ with respect to ex-post (or allocative) efficiency and a non-credible commitment on the government side is not needed.

Before concluding, it may be interesting to discuss this last point a bit further. To do so, let us briefly consider a modified setup which is closer to the usual idea of soft budget constraints. Suppose that $\Pi\left(y^{F B}\right)<\delta<S\left(y^{F B}\right)+\Pi\left(y^{F B}\right)$ so that future production is efficient but even renegotiation cannot hinder $P$ to shut down the firm unless $T_{I}$ is invented. Suppose further that the government can commit not to bail out a bankrupt private firm. ${ }^{22}$ Then, the private manager obtains only his redundancy payment $w_{0}$ when innovation fails; his equilibrium effort increases and $\underline{q}^{P}, \bar{q}^{P}$ decrease so that, as under public ownership, efficient investments can be attained only if $q$ is relatively small. Hence, it is unclear whether privatization really improves equilibrium incentives relative to public governance as has been argued in the relevant literature [for a survey, see Maskin (1999)]. At least in our setting, privatization plus a governmental non-

\footnotetext{
${ }^{22}$ Otherwise, the qualitative conclusions will be the same as in our model: in a state of the world where the entrepreneur goes bankrupt but ongoing production remains welfare-efficient, $G$ will bail out the firm and $M$ will receive some wage larger than his redundancy payment. Accordingly, his investment incentives go down relative to a situation where no bail-out occurs; see below.
} 
intervention commitment will in general not be a remedy to overcome inefficiencies that arise under public governance, even if the welfare-diminishing effect of ex-post inefficient outcomes can be ignored.

\section{Discussion and Concluding Remarks}

The results of our paper suggest that privatization can be the optimal governance structure even when the government is purely benevolent and behaves completely rational. If no viable standard technology exists, privatization cannot enhance welfare. However, in the possibly more realistic scenario where the firm remains profitable even if no innovative technology can be used, this result may be reversed. To illustrate, suppose

$$
S\left(y^{F B}\right)+\Pi\left(y^{F B}\right)>3 \delta>\Pi\left(y^{F B}\right),
$$

and recall that the standard technology remains viable with ex-ante probability $q \in[0,1]$. According to our previous findings, public governance then attains a firstbest outcome for any $q<q^{G}<1$, while inefficient investments prevail otherwise. Private governance leads to efficiency for any $q \geq \underline{q}^{P}$. Finally, if consumer surplus is relatively large so that $q^{G}<\underline{q}^{P}$, either regime is inefficient for values $q \in\left(q^{G}, \underline{q}^{P}\right)$. For these intermediate parameters, the government at date 0 chooses the ownership structure which triggers an investment as close as possible to $e^{F B}$. It is easy to check that this second-best governance structure is either private ownership and a wage contract slightly above $\Delta w=P_{B}$ (which minimizes overinvestments), or public ownership in combination with an optimal wage differential $\Delta w$ equal to $G_{B}$ (which minimizes underinvestments).

These implications are in line with empirical evidence and show that underinvestment under public governance can be explained even when the government is rational and signs efficient salary contracts with its management. Not only in this respect, an interesting special case is a situation where consumer surplus is very large relative to net profits. Then, $q^{G} \rightarrow 0$ whereas $\underline{q}^{P}, \bar{q}^{P} \rightarrow 1$ and the first best can only be attained when $q$ is close to one of the extreme values. In a broad intermediate range, the optimal governance mode trades off overinvestments that arise under private governance, and underinvestments when the firm remains public. 
Taken together, our results allow for a relatively clearcut interpretation. At least in industries where consumer surplus is high, privatization can be beneficial when the firm does not act under a severe threat to innovate production processes (i.e., if $q$ is high). Likewise, the more important consumer surplus, the smaller is the boundary level of $q$ and the harder it becomes to implement a first-best outcome under public governance. As obvious cases in question, consider utilities like garbage collection or water and electricity supply, or services like telecommunication and postal services. In fact, many of those formerly public enterprises have been privatized in most European countries over the last decade [see, for example, Martin and Parker (1997)].

It is also interesting to highlight some features of the present model which distinguish it from the previous theoretical literature on the benefits of privatization. First, since expost efficient decisions are taken under either governance structure, the government has no incentive to interfere into the operations of the privatized firm. This is particularly important because arguments in favor of privatization frequently require the government not to intervene ex post, even when this inaction is suboptimal. As already stated in the Introduction, the above mentioned soft-budget constraint argument starts from the idea that privatization generates a serious incentive for managerial effort because private owners go bankrupt when profits become negative. This line of reasoning requires the government to exhibit a sequentially irrational behavior. Specifically, it must commit not to bail out a bankrupt private firm ex post even if an intervention would improve welfare at the ex-post stage after managerial effort has been undertaken. ${ }^{23}$ If a non-credible commitment is impossible, however, a rational private manager anticipates a government intervention and therefore faces the same negligible shutdown threat as his public counterpart. As a consequence, private and public managers are subject to the same "soft budget constraint".

Conversely, the present paper has considered a situation where - even without government intervention - both possible governance structures reach an ex-post efficient production decision (recall that the government regulates the private firm efficiently); thus, the government has no reason to intervene for allocative reasons at any point in time. It also has no other motive to enter renegotiations between private owner and

\footnotetext{
${ }^{23}$ Segal (1998) shows that privatization enhances investments and can therefore be optimal when the private firm is not regulated ex post and thus able to accrue monopoly profits. In his model with complete information, this government behavior is not sequentially rational.
} 
manager because, under the proposed privatization procedure, these renegotiations do not affect the public purse. The paper therefore provides an argument in favor of privatization without relying upon strong commitment assumptions. This finding is not only of theoretical importance: empirical evidence suggests that government interventions (often rationalized by job securing motives) frequently arise when private firms are on the brink of bancruptcy.

Second, our approach is not based on assumed differences in bargaining behavior between both types of principal. Rather, it is the distinct set of states of the world in which bargaining (renegotiation) actually occurs that drives the results. At certain wage levels, the government is still willing to produce under a viable basic technology at the initial terms of contract. In contrast, the private owner credibly refuses to continue operation under this technology which renders renegotiation necessary. These differences in actual renegotiation in either regime, in turn, induce different equilibrium wages and thus trigger different optimal investment responses by the manager.

Finally, governance structures in our present model differ only in the objective function of the respective owner of the firm. This approach is in contrast to some of the leading models on privatization, which suppose that either informational structures or contractual possibilities vary among regimes: Schmidt (1996a,b) also assumes a benevolent government, but he supposes that privatization leads to asymmetric information between government and firm which now has superior knowledge on its production costs. Hart, Shleifer and Vishny (1997) implicitly assume that a public manager cannot be made the residual claimant for the firm's cost savings while a private manager-owner can.

Although these assumptions may be well motivated from an empirical point of view, we believe that the interplay between governance structures and economic performance becomes most transparent when the analysis allows for regime-independent environments. Admittedly, our results have been attained in a very simple and stylized setting which ignores many important considerations that arise in reality. Still, the paper may be a valuable first attempt to show that a transition to private governance can be efficient even if a rational government pursues welfare goals. 


\section{References}

Aghion, P. and J. Tirole (1994), "The Management of Innovation", Quarterly Journal of Economics: 109: 1185-1209.

Bös, D. (1991), Privatization: A Theoretical Treatment, Oxford: Oxford University Press.

Bös, D. and C. Lülfesmann (1998), "Holdups, Quality Choice, and the Achilles' Heel in Government Contracting", Discussion Paper A-481, University of Bonn.

Boycko, M., A. Shleifer and R.W. Vishny (1996), "A Theory of Privatisation", Economic Journal , 106: 309-319.

Boycko, M., A. Shleifer and R.W. Vishny (1996), "A Theory of Privatisation", Economic Journal , 106: 309-319.

Dixit, A.K. (1996), The Making of Economic Policy, Cambridge, Massachusetts: MIT Press.

Grossman, S.J. and O. Hart (1986),: "The Costs and Benefits of Ownership: A Theory of Vertical and Lateral Integration", Journal of Political Economy, 94: 691-719.

Hart, O. (1995), Firms, Contracts, and Financial Structure, Oxford: Oxford University Press.

Hart, O. and B. Holmström (1987), "The Theory of Contracts", in: Truman Bewley, ed.: Advances in Economic Theory, Fifth World Congress, Cambridge: Cambridge University Press.

Hart, O. and J. Moore (1999), "Foundations for Incomplete Contracts", Review of Economic Studies, 66: 115-138.

Hart, O., Shleifer, A. and R.W. Vishny (1997), "The Proper Scope of Government: Theory and an Application to Prisons", Quarterly Journal of Economics, 112: 1127-1161. 
Holmström, B. and J. Tirole (1989), "The Theory of the Firm", in: Schmalensee, R. and R.D. Willig, eds.: Handbook of Industrial Organization, Vol.1, Amsterdam: North Holland.

Kornai, J. (1986), "The Soft Budget Constraint", Kyklos, 39: 3-30.

Kornai, J., Maskin, E. and G. Roland (2002), "Understanding the Soft Budget Constraint", mimeo, UC Berkeley.

Laffont, J.-J. and J. Tirole (1993), A Theory of Incentives in Procurement and Regulation, Cambridge, Massachusetts: MIT Presss.

MacLeod, B. and J.M. Malcomson (1993), "Investments, Hold-Up, and the Form of Market Contract", American Economic Review, 83: 811-837.

Malcomson, J.M. (1997), "Contracts, Hold-Up, and Labor Markets", Journal of Economic Literature, 35: 1916-1957.

Martin, S. and D. Parker (1997), The Impact of Privatisation - Ownership and Corporate Performance in the UK, Routledge: London, New York.

Maskin, E. (1999), "Recent Theoretical Work on the Soft Budget Constraint", American Economic Review, 89: 421-425.

Megginson, W.-L., Nash, R.-C. and M. van Randenborgh (1994), "The Financial and Operating Performance of Newly Privatized Firms: An International Empirical Analysis", Journal of Finance, 49: 403- 452.

Megginson, W.-L. and J. M. Netter (2001), "From State to Market: A Survey of Emprirical Studies on Privatization", Journal of Economic Literature, 39: 321- 390.

Persson, T. and G. Tabellini (2000), Political Economics: Explaining Economic Policy, Cambridge, MA: MIT Press.

Schmidt, K.M. (1996a), "Incomplete Contracts and Privatization", European Economic Review, 40: 569-579. 
Schmidt, K.M. (1996b), "The Costs and Benefits of Privatization: An Incomplete Contracts Approach", Journal of Law, Economics and Organisation, 12: 1-24.

Segal, I. (1998), "Monopoly and Soft Budget Constraint", RAND Journal of Economics, 29: 596-609.

Segal, I. (1999), "Complexity and Renegotiations: A Foundation for Incomplete Contracts", Review of Economic Studies, 66: 57-82.

Shapiro, K. and R. Willig (1990), "Economic Rationales for the Scope of Privatization", in: E.N. Suleiman, and J.Waterbury (eds.), The Political Economy of Public Sector Reform and Privatization, Boulder, Colorado: Westview Press.

Shleifer, A. (1998), "State versus Private Ownership", Journal of Economic Perspectives, 12: 133-150.

Tirole, J. (1994), "The Internal Organization of Government", Oxford Economic Papers, 46: 1 - 29 .

Vickers, J. and G. Yarrow (1988), Privatization: An Economic Analysis, London and Cambridge: MIT Press.

Williamson, O.E. (1985), The Economic Institutions of Capitalism, New York: The Free Press. 